\title{
Applying Simplex Algorithm for Ship's Motion Simulation Optimization by Using Maneuvering Tests Data
}

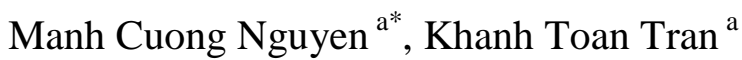 \\ ${ }^{a}$ Vietnam Maritime University, Hai Phong City, Vietnam \\ E-mail: *nmcuong@vimaru.vn
}

\begin{abstract}
This article demonstrates an effective method to find OHCs (optimal hydrodynamic coefficients) by applying the Simplex algorithm to reduce the errors of the ship's motion simulation. The solution is to determine OHCs, which are also the coefficients of the ship's motion equations. A ship's motion simulation model was programed by contributing the mathematical model of the ship's motion, applying the numerical method and MATLAB. In the optimization procedure, the form of Objective Function was contributed corresponding to the type of maneuvering test. The Sensitivity Analysis technique and Simplex algorithm are applied to filter and optimize the most sensitive hydrodynamic coefficients. The numerical model was validated by experimental maneuvering test data, including Turning Circle and Zigzag tests of Esso Bernicia 193000DWT Tanker. A good optimization solution was obtained: for Turning Circle test, after optimization, the ship's simulation trajectory is close to the experimental trajectory with a RMSD of $5.8 \mathrm{~m}$, which reduced from an original value of $69 \mathrm{~m}$. In the Zigzag test, the RMSD between the ship's simulation yaw angle and experimental data was reduced $17.3 \mathrm{deg}$ to $5.9 \mathrm{deg}$. The other optimization results, such as the convergence of Objective Function, the number of iteration of Optimization Variables, calculated time, etc. are accepted. Therefore, the Simplex algorithm can be applied quite effectively to optimize ship movement (ship's trajectory, the ship's yaw angle, etc.). By defining a common set of values by merging the optimal value of the most sensitive coefficients of two tests, which may be used for the other ship's motion simulation applications.
\end{abstract}

Keywords - ship's motion simulation; optimization technique; Simplex algorithm; hydrodynamic; experimental maneuvering.

\section{INTRODUCTION}

Ships are objects of considerable nonlinearity, operating in the ocean environment, so they are greatly influenced by random interference factors such as waves, wind, ocean currents [1]. Notably, the measurement and determination of kinematic parameters are complicated and confusing. Therefore, ships are the object of many scientists around the world interested in researching, and it is always an exciting challenge for the community of scientists when studying the ship's motion control. In particular, when a ship navigates in a narrow channel, the ship will be affected by the limitations of the channel, namely: the width of the navigation and the depth of the channel [2]. These factors directly affect the maneuverability of the ship, such as rotation, inertia, and speed of the ship. In addition, when the ship is moving in the narrow channel, there are also physical phenomena such as shore effect, squat, and hydrodynamic interaction. Moreover, tankers are special cargo ships because of their potential to cause serious pollution to the marine environment if any accident occurs, so the safety of tankers is higher than that of conventional cargo ships [3], [4]. When maneuvering and traveling in and out of narrow channels, the operators must be proficient, and the ship maneuvering system must work with high reliability [5].

The 1978 STCW Convention and its amendments in 2010 recognized the importance and provided for the increased use of cockpit simulation in maritime professional training [6]. In addition to statutory requirements, the demand for simulated training in the world has also become urgent, requiring maritime training institutions to equip cockpit simulations capable of simulating different types of propulsion [7]. The maneuvering simulation system can also be explored in the feasibility study of ship design, port design, and navigational channel [8]. This application is applicable to existing ships as well as during the design process. To do this, it is necessary to set up a suitable math model for ship motions and meet the accuracy of each specific ship. The artificial brain of a maneuvering simulation system is the math model for ship motion so that realism can be guaranteed [9]. In the problem of controlling ship movement, the first thing is to understand the dynamics of the control object as well as its relationship to the surrounding environment [10]. The result of learning about a control object is usually a mathematical model describing its 
kinematic properties. Since then, based on this mathematical model and the requirements for the desired control quality, it is proposed that the appropriate control method [11].

On the other hand, there have been many mathematical models that were introduced and developed over a long time with the application, adjusting many different predictive methods, and becoming very complicated. Therefore, the development of mathematical models suitable for ships should be more concerned, especially tankers with quite specialized propulsion systems [12]. It is challenging to optimize the ship trajectory simulation; one of the solutions is to identify OHCs that are in the ship's motion equations. The application of optimization technique with SQP and BFGS algorithms was made for this problem by T. Khang Toan [13] and Wang et al. [10]. In this paper, we introduce another optimization algorithm carrying out by an effective way to calculate OHCs by applying the Simplex algorithm for ship trajectory simulation based on ship maneuvering test data. As the previous researches, this procedure is achieved efficiently through 3 steps as follows [14]:

- Ship motion equations (in 3 DOF corresponding to surge-sway-yaw motions, Figure 1) are resolved by the numerical method to obtain the motion components such as ship position, velocity, yaw angle, hydrodynamic forces and moment, etc. The original value of ship hydrodynamic coefficients (HCs) are used in this step.

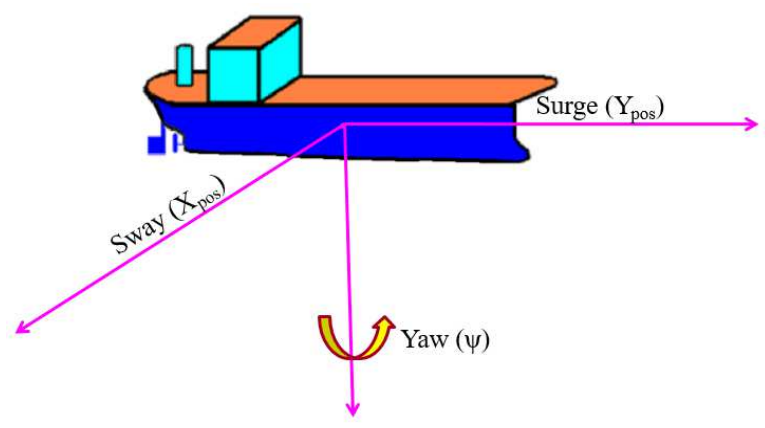

Fig. 1 Ship's motion components

- Applying the sensitivity analysis to filter the most sensitive HCs that have the most influence on the change of ship trajectory;

- Applying the Simplex algorithm to find the optimal value of the most sensitive HCs.

\section{MATERIAL AND METHOD}

\section{A. Mathematical Model}

The ship motion equations in 3 DOF are written as follows [15], [16]:

$$
\begin{gathered}
\dot{u}-v r=g X^{\prime \prime} \\
\dot{v}+u r=g Y^{\prime \prime} \\
\left(L k_{z}^{\prime \prime}\right) \cdot 2 \dot{r}=g L N^{\prime \prime}
\end{gathered}
$$

where: $u$ and $v$ are the surge and sway velocity respectively; $\dot{u}$ is the surge velocity and $\dot{v}$ is the sway velocity; $r$ is the yaw velocity; $\dot{r}$ is the yaw acceleration; $g$ is the gravity; $L$ is the length between perpendiculars of ship; $k_{Z}^{\prime \prime}=\frac{1}{L} \sqrt{\frac{I_{Z}}{m}}$ is the non-dimensional radius of gyration, $I_{z}$ is the inertial moment of ship.

$X^{\prime}, Y^{\prime}, N^{\prime \prime}$ are the non-dimensional forces and moments respectively that are written as follows:

$$
\begin{aligned}
& g . X^{\prime \prime}=X_{\dot{u}}^{\prime \prime} \dot{u}+\frac{1}{L} X_{u|u|}^{\prime \prime}|u| u\left|+\frac{1}{L} X_{v r}^{\prime \prime} v r+\frac{1}{L} X_{v v}^{\prime \prime} v\right| v \mid \\
& +\frac{1}{L} X_{c|c| \delta \delta} c|c| \delta^{2}+\frac{1}{L} X_{c|c| \beta \delta} c|c| \beta \delta+g T^{\prime \prime}\left(1-t_{d}\right) \\
& +\frac{1}{L} X_{\dot{u} \xi}^{\prime \prime} \dot{u} \xi+\frac{1}{L} X_{|u| u \xi}^{\prime \prime}|u| u \xi+\frac{1}{L} X_{v r \xi}^{\prime \prime} v r \xi+\frac{1}{L} X_{v v \xi \xi}^{\prime \prime} v^{2} \xi^{2} \\
& g . Y^{\prime \prime}=Y_{\dot{v}}^{\prime \prime} \dot{v}+\frac{1}{L} Y_{u v}^{\prime \prime} u v+\frac{1}{L} Y_{|v| v}^{\prime \prime}|v| v+\frac{1}{L} Y_{|c| c \delta}^{\prime \prime}|c| c \delta+\frac{1}{L} Y_{u r}^{\prime \prime} u r \\
& +\frac{1}{L} Y_{|c| c|\beta| \beta \delta}^{\prime \prime}|c| c|\beta| \beta \delta+Y_{T}^{\prime \prime} g T+\frac{1}{L} Y_{u r \xi}^{\prime \prime} u r \xi+\frac{1}{L} Y_{u v \xi}^{\prime \prime} u v \xi \\
& +Y_{\dot{v} \xi}^{\prime \prime} \dot{u} \xi+\frac{1}{L} Y_{|v| v \xi|v| v \xi+\frac{1}{L} Y_{|c| c|\beta| \beta \delta \xi}^{\prime \prime}|c| c|\beta| \beta \delta \xi} \\
& \text { g.L.N" }=\frac{1}{L^{2}} N_{\dot{r}}^{\prime \prime} \dot{r}+\frac{1}{L^{2}} N_{u v}^{\prime \prime} u v+\frac{1}{L} N_{|v| r}^{\prime \prime}|v| r \\
& +\frac{1}{L^{2}} N_{|c| c \delta}^{\prime \prime}|c| c \delta+\frac{1}{L} N_{u r}^{\prime \prime} u r+\frac{1}{L^{2}} N_{|c| c|\beta| \beta \delta}^{\prime \prime}|c| c|\beta| \beta \delta \\
& +\frac{1}{L} N_{T}^{\prime \prime} g T+\frac{1}{L} N_{u r \xi}^{\prime \prime} u r \xi+N_{\dot{r} \xi}^{\prime \prime} \dot{r} \xi+\frac{1}{L^{2}} N_{u v}^{\prime \prime} \xi u v \xi \\
& +\frac{1}{L} N_{v r \xi}^{\prime \prime} r v \xi+\frac{1}{L^{2}} N_{|c| c|\beta| \beta|\delta| \xi|c| c|\beta| \beta|\delta| \xi}^{\prime \prime}
\end{aligned}
$$

where: $X_{\dot{u}}^{\prime \prime}, X_{u|u|}^{\prime \prime}, \ldots, Y_{\dot{v}}^{\prime \prime}, Y_{u v}^{\prime \prime}, \ldots, N_{\dot{r}}^{\prime \prime}, N_{u v}^{\prime \prime}, \ldots, N_{|c| c|\beta| \beta|\delta| \xi}^{\prime \prime}$ are the non-dimensional ship's HCs, which can be calculated by Simplex algorithm; $\delta$ is the rudder angle; $t_{d}$ is the thrust deduction coefficient; $\beta=v / u ; \xi=T_{s} /\left(h-T_{s}\right)$.

where: $h$ is the water depth; $T$ ” is the non-dimensional propeller thrust given by:

$$
T^{\prime \prime}=\frac{1}{g L} T_{u и}^{\prime \prime} u^{2}+\frac{1}{g} T_{u n}^{\prime \prime} u n+\frac{L}{g} T_{|n| n \mid}^{\prime \prime}|n| n
$$

where: $T_{u u}, T_{u n}$ and $T_{|n| n}$ are HCs; $n$ is the engine speed; $c$ is the flow velocity at the rudder estimated by:

$$
c^{2}=c_{u n}^{2} u n+c_{n n}^{2} n^{2}
$$

where: $c_{u n}$ and $c_{n n}$ are the hydrodynamic coefficients.

\section{B. Numerical Method}

1) Ship's motion simulation: The vector of ship's motion state $(x)$ including the motion variables are computed [13], [17]-[19]:

$$
x=\left[u v r X_{p o s} Y_{p o s} \Psi \delta n\right]^{T}
$$

$x$ is calculated in a nonlinear time-varying matrix:

$$
\dot{x}=f\left(x, u_{c}, t\right)
$$


where: $t$ is the real-time; $X_{\text {pos }}$ and $Y_{p o s}$ are the coordinates of ship in $O X$-axis and $O Y$-axis of the earth-frame respectively; $u_{c}=\left[\begin{array}{ll}\delta_{c} & n_{c}\end{array}\right]^{T}$ is the control input; $\delta_{\mathrm{c}}$ is the commanded rudder angle; $n_{c}$ is the commanded shaft velocity; $\dot{\mathbf{x}}=[\dot{u} \dot{v} \dot{r}$

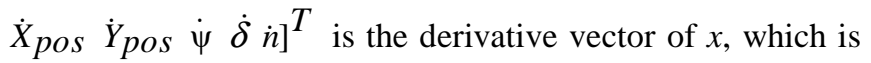
computed simultaneously by solving the ship motion equations by the Runge-Kutta 4th order method (RKF45).

2) Ship motion simulation optimization: For the optimization resolution, an Objective Function (Fobj) is minimized to identify ship hydrodynamic coefficients.

The optimization problem is resolved as follows [4]:

$$
\text { Minimize: } F_{o b j}=\left(\sum_{i=1}^{N} f_{i}(\alpha)^{2}\right)^{1 / 2}
$$

With: $\alpha=\left[\alpha_{1}, \alpha_{2}, \ldots, \alpha_{N}\right]^{T}$

where: $\alpha$ is the vector of optimization variables which represents the ship hydrodynamic coefficients to be determined; $N$ is the number of variables; $f_{i}(\alpha)$ is the deviation function between simulation and experimental data of ship maneuvering tests.

The above optimization problem will be solved by applying the Simplex algorithm. During the numerical resolution, the Objective Function $\left(F_{o b j}\right)$ is used, and the gradient values of $F_{o b j}$ concerning the vector $\alpha$ that will be updated through each calculation loop.

In this study, two maneuvering tests, including Turning Circle and Zigzag tests [10] were used as the validation tests. Thus, the formulation of $F_{o b j}$ is contributed depending on each test as follows:

3) Turning circle test [11]:

$$
F_{o b j}=\left(\sum_{i=1}^{N_{p}} f_{i}(\alpha)^{2}\right)^{1 / 2}=\left(\sum_{i=1}^{N_{p}} \Delta S_{i}^{2}\right)^{1 / 2}
$$

where: $\Delta S_{i}^{2}$ is the square root of the difference between the computed and the experimental ship trajectories, which depends on ship hydrodynamic coefficients $\alpha$. It reads:

$$
\Delta S_{i}^{2}=\left(x_{i}^{c a l}-x_{i}^{e x p}()^{2}\left(y_{i}^{c a l}-y_{i}^{e x p}()^{2}\right)\right)
$$

where: $c a l$ and exp are simulated and experimental maneuvering test data respectively, $\left(x_{i}, y_{i}\right)$ are the coordinates of the point $i$ on the trajectory, and $N_{p}$ is the number of pairs of points to be optimized.

For analyzing the discrepancy of trajectory, we used the Root Mean Square Deviation (RMSD) given by:

$$
\Delta S_{(R M S D)}=\left(\frac{1}{N} \sum_{i=1}^{N} \Delta S_{i}^{2}\right)^{1 / 2}
$$

where: $\Delta S_{i}^{2}$ is given by Eq. (10); $N$ is the total of points to be optimized.

4) Zigzag test [20]:

The expression of $F_{o b j}$ :

$$
F_{o b j}=\left(\sum_{i=1}^{N} f_{i}(\alpha)^{2}\right)^{1 / 2}=\left(\sum_{i=1}^{N}\left(\psi_{i}^{c a l}-\psi_{i}^{\exp }\right)^{2}\right)^{1 / 2}
$$

where: $\psi_{i}$ is the yaw angle, which also depends on HCs $\alpha$; $\mathrm{Np}$ is pairs of points to be approximated.

The Root Mean Square Deviation (RMSD) of the ship's yaw angle (between simulated and experimental data) given by:

$$
\Delta \psi_{(R M S D)}=\left(\frac{1}{N} \sum_{i=1}^{N} \Delta \psi_{i}^{2}\right)^{1 / 2}
$$

where: $\Delta \psi_{i}=\psi_{i}^{c a l}-\psi_{i}^{e x p} ; N$ is the total of points to be optimized.

\section{Ship Parameters}

The validation of this study is carried out by using the experimental maneuvering test data of Esso Bernicia 193000DWT Tanker [17] (Figure 2), where the ship parameters are given in Table 1 , and the 35 hydrodynamic coefficients are given in Table 2 .

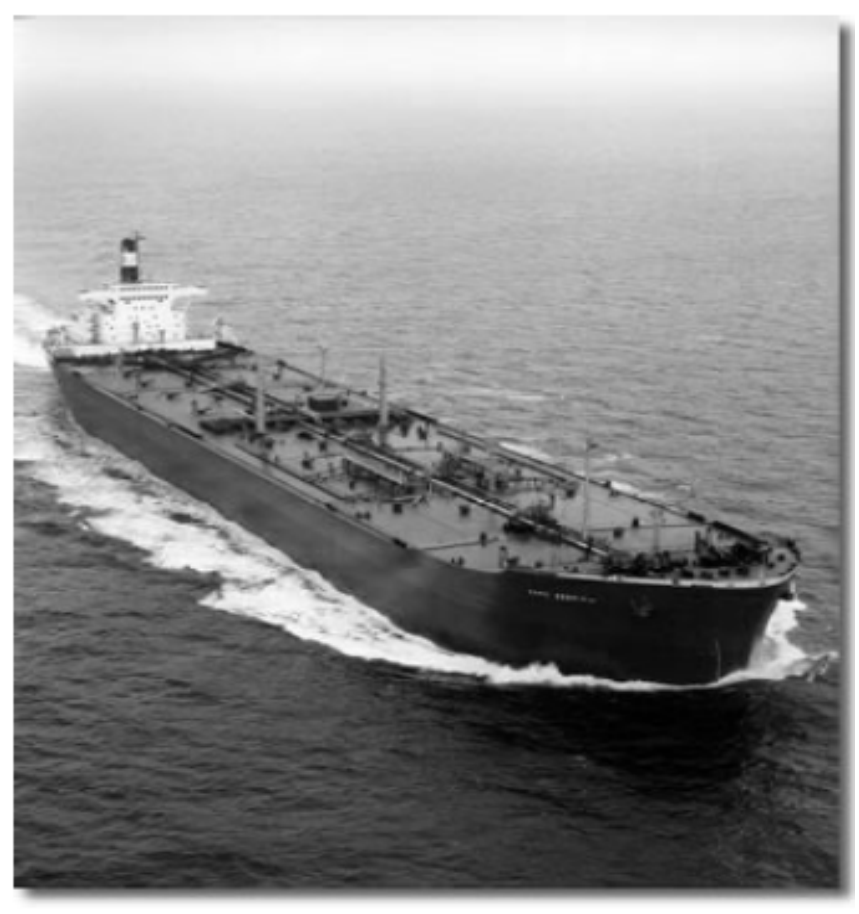

Fig. 2 Esso Bernicia 193000DWT Tanker [21]

TABLE I

PARAMETERS OF ESSO BERNICIA 193000DWT TANKER

\begin{tabular}{|c|c|c|c|}
\hline Parameters & Symbol & Unit & Values \\
\hline $\begin{array}{c}\text { Length between } \\
\text { perpendicular }\end{array}$ & Lpp & $\mathrm{m}$ & 304.8 \\
\hline Draft to design waterline & $\mathrm{T}$ & $\mathrm{m}$ & 18.46 \\
\hline Beam & $\mathrm{B}$ & $\mathrm{m}$ & 47.17 \\
\hline Displacement & $\nabla$ & $\mathrm{m}^{3}$ & 220,000 \\
\hline Block coefficient & $\mathrm{CB}$ & - & 0.83 \\
\hline Design speed & $\mathrm{U} 0$ & $\mathrm{knots}$ & 16 \\
\hline $\begin{array}{c}\text { Nominal speed of } \\
\text { propeller }\end{array}$ & $\mathrm{n}$ & $\mathrm{rpm}$ & 80 \\
\hline
\end{tabular}


TABLE II

HCS OF ESSO BERNICIA 193000DWT TANKER [17]

\begin{tabular}{|c|c|c|}
\hline ID No. & Hyd. Coefficient & Initial Value \\
\hline 1 & $X_{\dot{u}}^{\prime \prime}$ & -0.05 \\
\hline 2 & $X_{v r}^{\prime \prime}$ & 1.020 \\
\hline 3 & $Y_{\dot{v}}^{\prime \prime}$ & -0.020 \\
\hline 4 & $Y_{|c| c|\beta| \beta \delta}^{\prime \prime}$ & -2.16 \\
\hline 5 & $Y_{T}^{\prime \prime}$ & 0.040 \\
\hline 6 & $N_{T}^{\prime \prime}$ & -0.020 \\
\hline 7 & $N_{\dot{r}}^{\prime \prime}$ & -0.0728 \\
\hline 8 & $Y_{|v| v}^{\prime \prime}$ & -2.4 \\
\hline 9 & $N_{|v| r}^{\prime \prime}$ & -0.3 \\
\hline 10 & $X_{|v| v}^{\prime \prime}$ & 0.3 \\
\hline 11 & $Y_{u v}^{\prime \prime}$ & -1.205 \\
\hline 12 & $N_{u v}^{\prime \prime}$ & -0.451 \\
\hline 13 & $X_{\dot{u} \xi}^{\prime \prime}$ & -0.05 \\
\hline 14 & $Y_{\dot{v} \xi}^{\prime \prime}$ & -0.378 \\
\hline 15 & $Y_{u r \xi}^{\prime \prime}$ & 0.182 \\
\hline 16 & $N_{u r \xi}^{\prime \prime}$ & -0.047 \\
\hline 17 & $X_{v r \xi}^{\prime \prime}$ & 0.378 \\
\hline 18 & $Y_{|v| v \xi}^{\prime \prime}$ & -1.5 \\
\hline 19 & $N_{v r \xi}^{\prime \prime}$ & -0.12 \\
\hline 20 & $Y_{|c| c \delta}^{\prime \prime}$ & 0.208 \\
\hline 21 & $Y_{u v \xi}^{\prime \prime}$ & 0 \\
\hline 22 & $N_{u v \xi}^{\prime \prime}$ & -0.241 \\
\hline 23 & $X_{c|c| \beta \delta}^{\prime \prime}$ & 0.152 \\
\hline 24 & $N_{c|c| \delta}^{\prime \prime}$ & -0.098 \\
\hline 25 & $X_{v v \xi \xi}^{\prime \prime}$ & 0.0125 \\
\hline 26 & $Y_{|c| c|\beta| \beta \delta}^{\prime \prime}$ & -2.16 \\
\hline 27 & $N_{|c| c|\beta| \beta \delta}^{\prime \prime}$ & 0.688 \\
\hline 28 & $Y_{|c| c|\beta| \beta \delta \xi}^{\prime \prime}$ & -0.191 \\
\hline 29 & $N_{|c| c|\beta| \beta|\delta| \xi}^{\prime \prime}$ & 0.344 \\
\hline 30 & $Y_{\mathrm{ur}}^{\prime \prime}$ & 0.248 \\
\hline 31 & $N_{\text {ur }}^{\prime \prime}$ & -0.207 \\
\hline 32 & $X_{\mathrm{u}|\mathrm{u}|}^{\prime \prime}$ & -0.0377 \\
\hline 33 & $N_{\dot{r} \xi}^{\prime \prime}$ & -0.0045 \\
\hline 34 & $X_{|\mathrm{u}| \mathrm{u} \xi}^{\mathrm{n} \xi}$ & -0.0061 \\
\hline
\end{tabular}

\begin{tabular}{|c|c|c|}
\hline ID No. & Hyd. Coefficient & Initial Value \\
\hline 35 & $X_{c|c| \delta \delta}^{\prime \prime}$ & -0.093 \\
\hline
\end{tabular}

D. Data of Ship Maneuvering Tests at Sea

The experimental input parameters of ship maneuvering tests, including Turning Circle and Zigzag, are given in Table 3.

TABLE III

EXPERIMENTAL INPUT PARAMETERS OF 2 MANEUVERING TESTS OF ESSO BERNICIA 193000DWT TANKER

\begin{tabular}{|l|c|c|}
\hline \multicolumn{1}{|c|}{$\begin{array}{c}\text { Experimental input } \\
\text { parameters }\end{array}$} & $\begin{array}{c}\text { Turning Circle } \\
\text { test }\end{array}$ & $\begin{array}{c}\text { Zigzag } \\
\text { test }\end{array}$ \\
\hline$\left(x_{0}, y_{0}\right)$ : initial ship's position & $(0.0) \mathrm{m}$ & $(0.0) \mathrm{m}$ \\
\hline$\psi_{0}:$ initial yaw angle & $0 \mathrm{deg}$ & $0 \mathrm{deg}$ \\
\hline $\begin{array}{l}U_{0}: \text { initial advance velocity } \\
\text { of ship }\end{array}$ & $5.3 \mathrm{~m} / \mathrm{s}$ & $7.5 \mathrm{~m} / \mathrm{s}$ \\
\hline$\delta_{0}:$ initial rudder angle & $0 \mathrm{deg}$ & $0 \mathrm{deg}$ \\
\hline$\dot{\delta}_{\text {max }}:$ maximal rotation & $2.7 \mathrm{deg} / \mathrm{s}$ & $2.7 \mathrm{deg} / \mathrm{s}$ \\
velocity of rudder & $57 \mathrm{rpm}$ & $80 \mathrm{rpm}$ \\
\hline$n_{0}:$ initial shaft velocity & $57 \mathrm{rpm}$ & $80 \mathrm{rpm}$ \\
\hline$n_{c}:$ shaft velocity command & $-35 \mathrm{deg}$ & {$[-20,+20] \mathrm{deg}$} \\
\hline$\delta_{c}:$ rudder angle command & \multicolumn{2}{|l}{} \\
\hline
\end{tabular}

\section{RESULTS AND DISCUSSION}

\section{A. Ship's Motion Simulation}

The simulation results of the ship's trajectory in Turning Circle test and ship's yaw/rudder angles in the Zigzag test $[1,13,14]$ are given in Figure 3 and Figure 4 respectively.

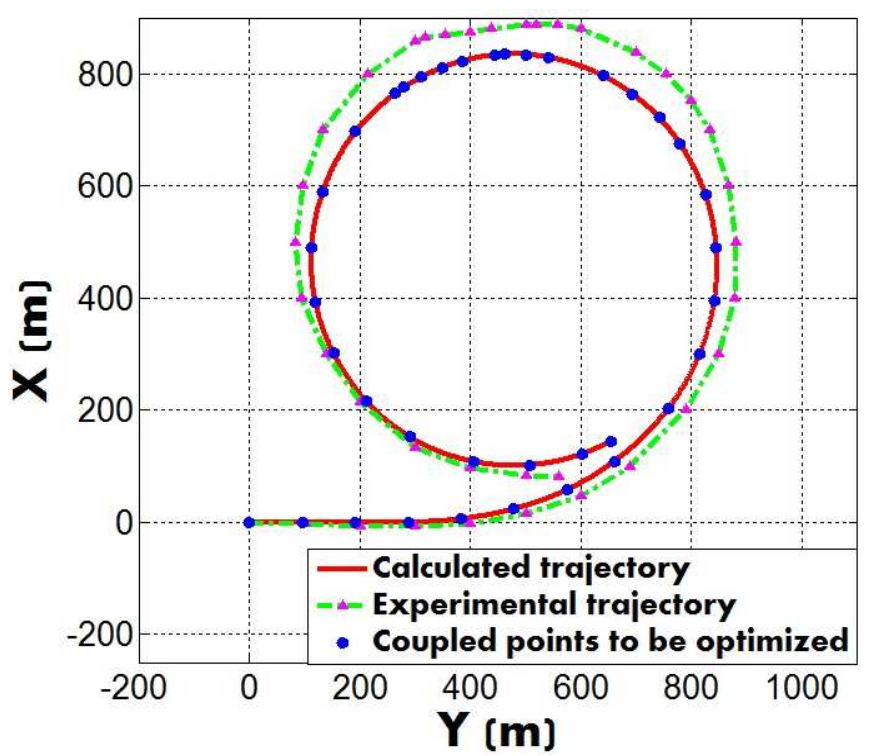

Fig. 3 Simulation (calculated) result of the ship's trajectory in Turning Circle test 


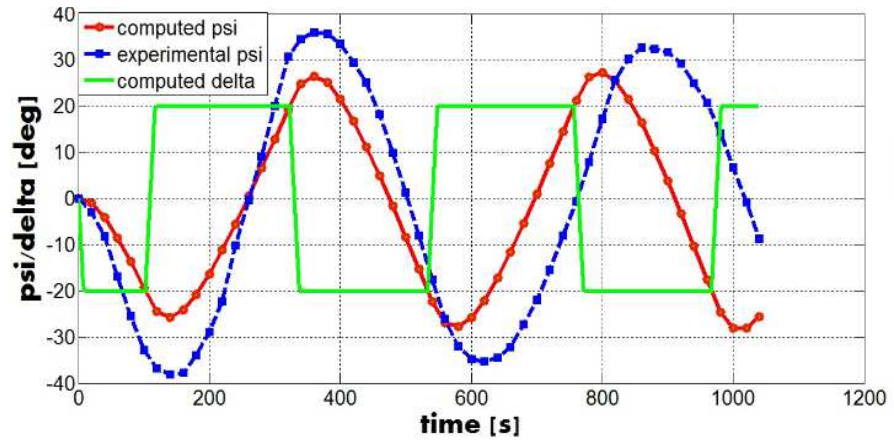

Fig. 4 Simulation (computed) result of the ship's yaw (psi) and rudder (delta) angles in the Zigzag test.

\section{B. Sensitivity Analysis of $\mathrm{HCs}$}

The most sensitive HCs [22] of each maneuvering test are determined and summarized in Table 4 and Table 5.

TABLE IV

THE MOST SENSITIVE HCS OF TURNING CIRCLE TEST

\begin{tabular}{|c|c|c|}
\hline ID No. & Hyd. Coefficient & Initial Value \\
\hline 6 & $N_{T}^{\prime \prime}$ & -0.020 \\
\hline 15 & $Y_{u r \xi}^{\prime \prime}$ & 0.182 \\
\hline 16 & $N_{u r \xi}^{\prime \prime}$ & -0.047 \\
\hline 20 & $Y_{|c| c \delta}^{\prime \prime}$ & 0.208 \\
\hline 22 & $N_{u v \xi}^{\prime \prime}$ & -0.241 \\
\hline 23 & $X_{c|c| \beta \delta}^{\prime \prime}$ & 0.152 \\
\hline 24 & $N_{c|c| \delta}^{\prime \prime}$ & -0.098 \\
\hline 31 & $N_{\mathrm{ur}}^{\prime \prime}$ & -0.207 \\
\hline 34 & $X_{|\mathrm{u}| \mathrm{u} \xi}^{\prime \prime}$ & -0.0061 \\
\hline 35 & $X_{c|c| \delta \delta}$ & -0.093 \\
\hline
\end{tabular}

TABLE V

THE MOST SENSITIVE HYDRODYNAMIC COEFFICIENTS OF ZIGZAG TEST

\begin{tabular}{|c|c|c|}
\hline ID No. & Hyd. Coefficient & Initial Value \\
\hline 5 & $Y_{T}^{\prime \prime}$ & 0.040 \\
\hline 6 & $N_{T}^{\prime \prime}$ & -0.020 \\
\hline 7 & $N_{\dot{r}}^{\prime \prime}$ & -0.0728 \\
\hline 15 & $Y_{u r \xi}^{\prime \prime}$ & 0.182 \\
\hline 16 & $N_{u r \xi}^{\prime \prime}$ & -0.047 \\
\hline 22 & $N_{u v \xi}^{\prime \prime}$ & -0.241 \\
\hline 24 & $N_{c|c| \delta}^{\prime \prime}$ & -0.098 \\
\hline 32 & $X_{\mathrm{u}|\mathrm{u}|}^{\prime \prime}$ & -0.0377 \\
\hline 33 & $N_{\dot{r} \xi}^{\prime \prime}$ & -0.0045 \\
\hline 34 & $X_{|\mathrm{u}| \mathrm{u} \xi}^{\prime \prime}$ & -0.0061 \\
\hline
\end{tabular}

C. Identifying the Optimal Value of the Most Sensitive HCs by Simplex Algorithm

1) Turning Circle test: The evolution of the Objective Function is shown in Figure 5.

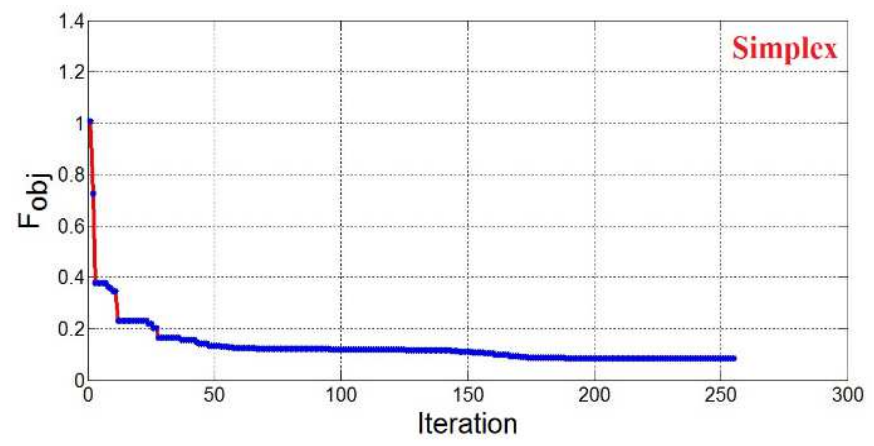

Fig. 5 Convergence of Objective Function (FoBJ) obtained by the Simplex algorithm in Turning Circle test.

The evolution of the OHC (optimization variables) applying the Simplex algorithm is shown in Figures 5. A comparison of the ship's trajectory before and after the optimization procedure is presented in Figure 6.

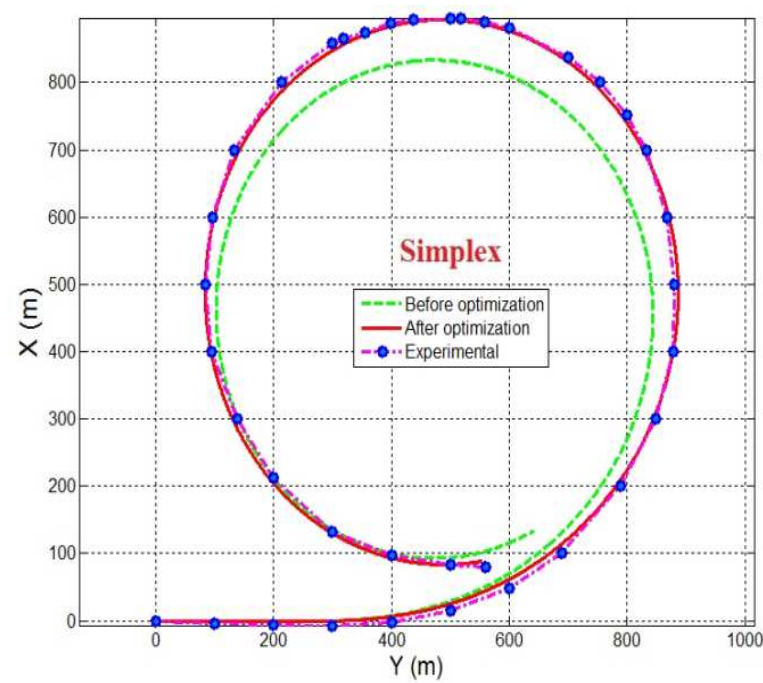

Fig. 6 Ship's trajectory optimization obtained by Simplex algorithm in Turning Circle test

Before optimization, RMSD of ship's trajectory between experimental and simulation data is: $\Delta S_{(R M S D)}=68 \mathrm{~m}$. After optimization procedure, this value is reduced to $5.8 \mathrm{~m}$. As shown in Figure 7, after optimization procedure by applying Simplex algorithm, the simulated trajectory of ship is close to experimental trajectory. The important optimal solutions obtained by Simplex algorithm are summarized in Table 6 . The optimal value of HCs obtained by Simplex algorithm is presented in Table 7. As shown in Table 6, the minimum value of the Objective Function obtained by Simplex algorithm after convergence, which is 0.085 (minimized from 1). This shows that a very good result was obtained and Simplex algorithm is suitable to ship's trajectory optimization problem. 

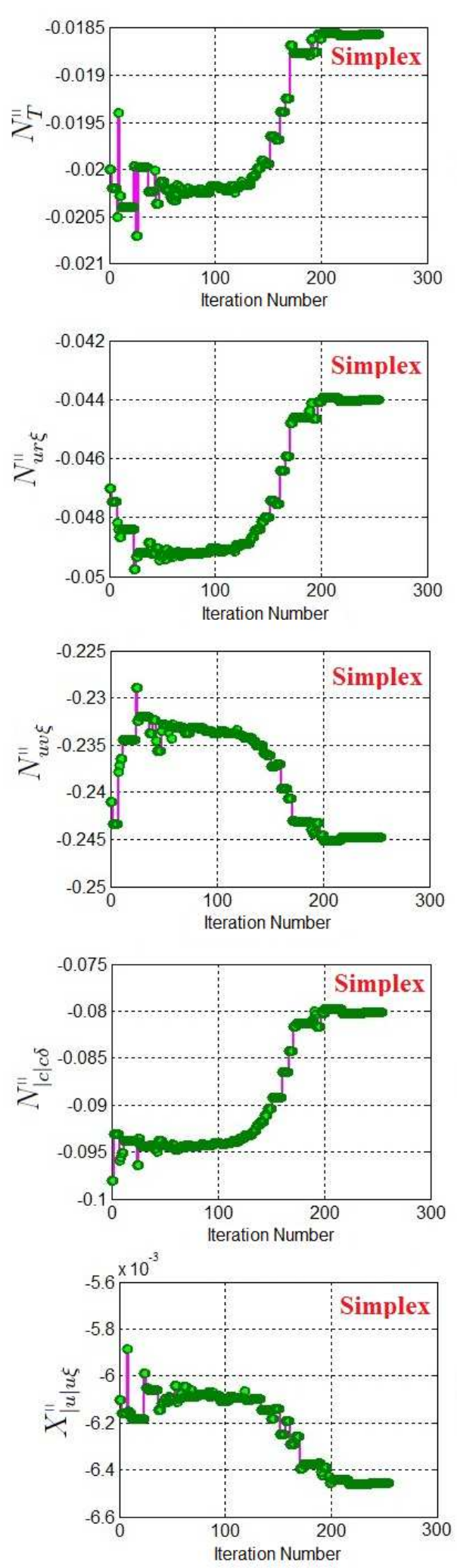
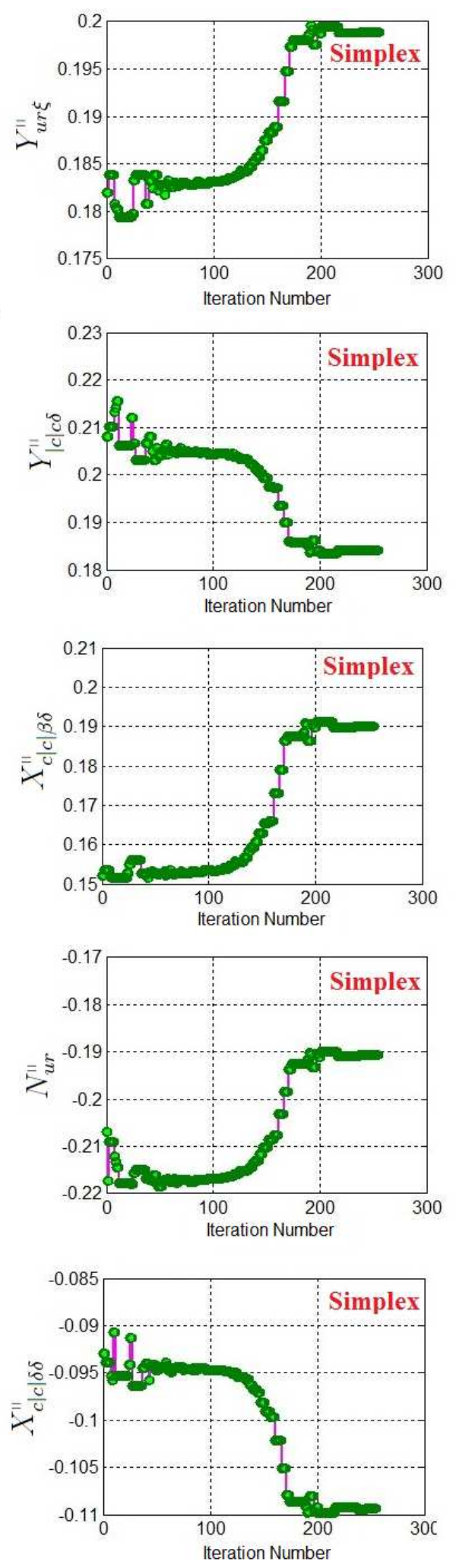

Fig. 7 Evolution of the optimal HCs obtained by Simplex algorithm in Turning Circle test 

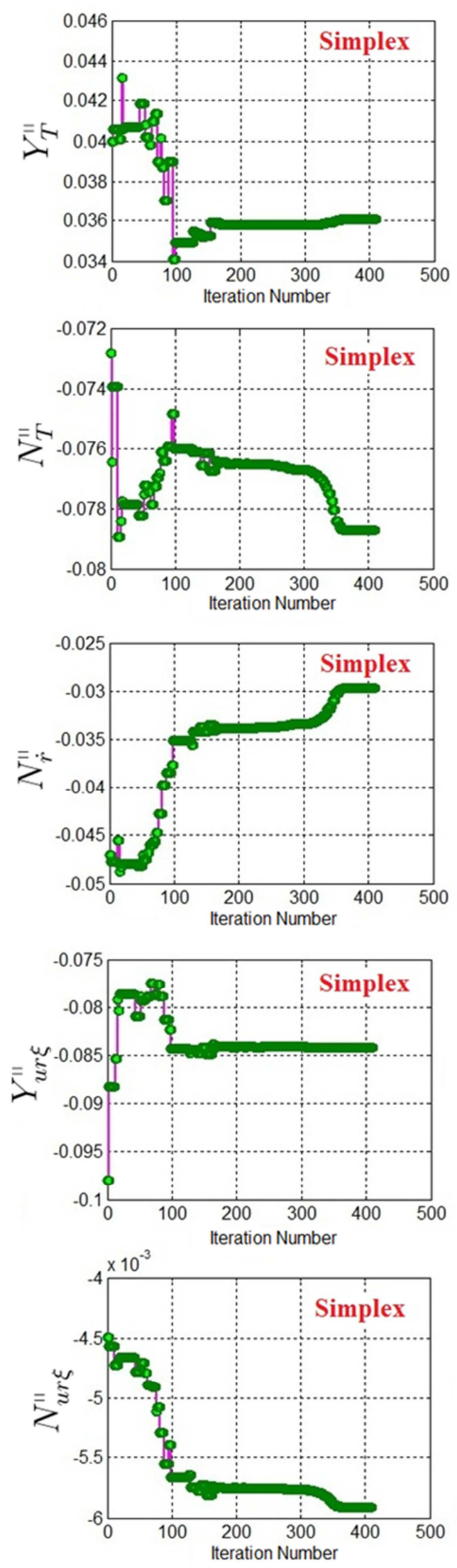
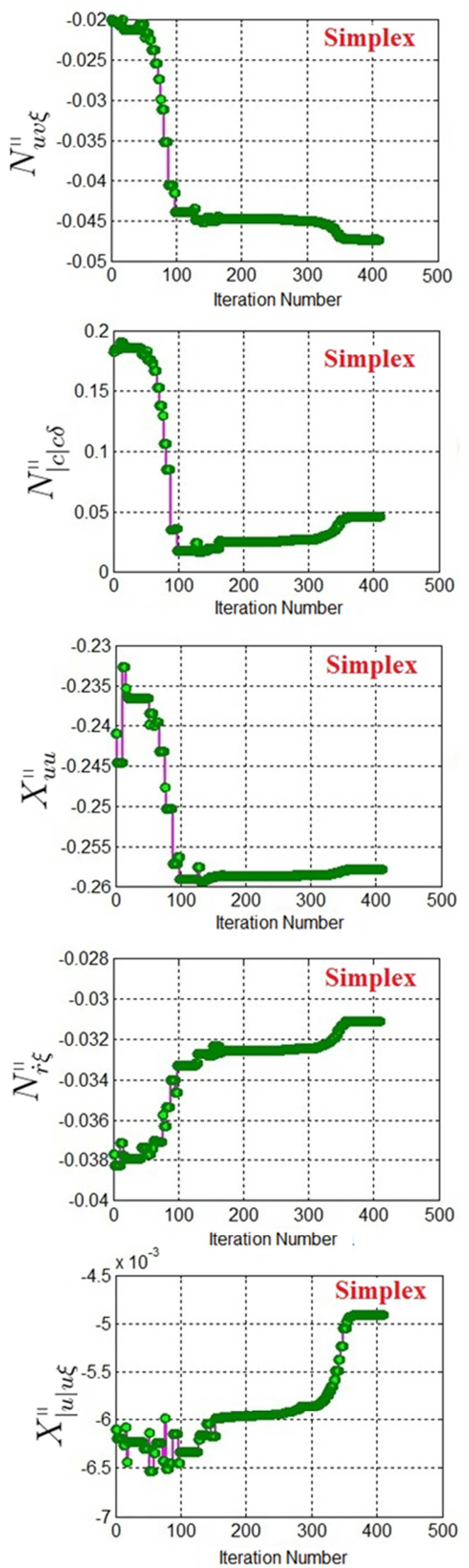

Fig. 8 Evolution of the optimal HCs obtained by Simplex algorithm in Zigzag test. 
TABLE VI

NUMERICAL RESULTS OF THE OPTIMIZATION PROCEDURE FOR TURNING CIRCLE TEST

\begin{tabular}{|c|c|}
\hline Parameter & Value \\
\hline $\begin{array}{l}\text { Objective Function Error: } \\
\qquad\left\|F_{o b j}^{\text {iter }}-F_{o b j}^{\text {iter }-1}\right\|\end{array}$ & $1 \times 10^{-4}$ \\
\hline Optimization Variable Error: $\left\|\alpha_{S}^{\text {iter }}-\alpha_{S}^{\text {iter-1 }}\right\|$ & $1 \times 10^{-4}$ \\
\hline Maximum Number of Iterations & 254 \\
\hline $\begin{array}{c}\text { Minimum Value of Objective Function (minimized } \\
\text { from } 1.000): F_{o b j}\end{array}$ & 0.085 \\
\hline $\begin{array}{l}\text { RMSD of ship's trajectory (minimized from } 68 \mathrm{~m} \text { ): } \\
\qquad \Delta S_{(R M S D)}\end{array}$ & $5.8 \mathrm{~m}$ \\
\hline
\end{tabular}

TABLE VII

OPTIMAL VALUE OF HCS IN TURNING CIRCLE TEST.

\begin{tabular}{|c|c|c|c|}
\hline ID No. & Hyd. Coefficient & Initial Value & $\begin{array}{c}\text { Optimal } \\
\text { Value }\end{array}$ \\
\hline 6 & $N_{T}^{\prime \prime}$ & -0.020 & -0.018 \\
\hline 15 & $Y_{u r \xi}^{\prime \prime}$ & 0.182 & 0.212 \\
\hline 16 & $N_{u r \xi}^{\prime \prime}$ & -0.047 & -0.046 \\
\hline 20 & $Y_{|c| c \delta}^{\prime \prime}$ & 0.208 & 0.190 \\
\hline 22 & $N_{u v \xi}^{\prime \prime}$ & -0.241 & -0.233 \\
\hline 23 & $X_{c|c| \beta \delta}^{\prime \prime}$ & 0.152 & 0.190 \\
\hline 24 & $N_{c|c| \delta}^{\prime \prime}$ & -0.098 & -0.082 \\
\hline 31 & $N_{\mathrm{ur}}^{\prime \prime}$ & -0.207 & -0.186 \\
\hline 34 & $X_{|\mathrm{u}| \mathrm{u} \xi}^{\mathrm{n} \xi}$ & -0.0061 & -0.0061 \\
\hline 35 & $X_{c|c| \delta \delta}^{\prime \prime}$ & -0.093 & -0.110 \\
\hline
\end{tabular}

2) Zigzag test: By applying Simplex algorithm with the same optimization procedure as for Turning Circle test, the evolution of the optimal HCs in Zigzag test is obtained and shown in Figures 8. Convergence of the Objective Function is presented in Figure 9.

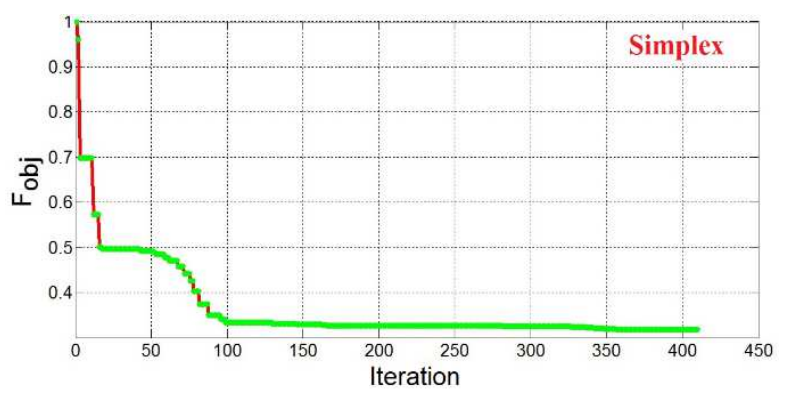

Fig. 9 Convergence of Objective Function (Fobj) obtained by Simplex algorithm in Zigzag test.

Comparison of ship's yaw angle before and after optimization procedure is shown in Figure 10.

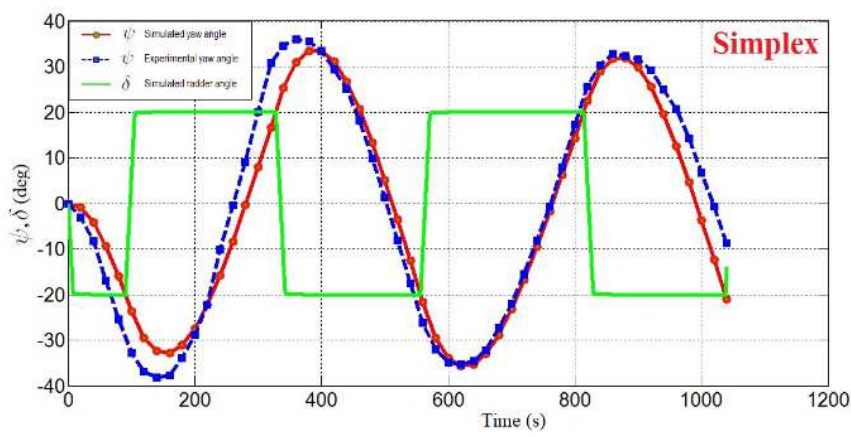

Fig. 10 Ship's yaw angle optimization in the Zigzag test.

Before optimization, RMSD of ship's yaw angle between experimental and simulation data is: $\Delta \psi_{(R M S D)}=17.3 \mathrm{deg}$. After the optimization procedure, this value is reduced to 5.9 deg. The important optimal solutions obtained by Simplex algorithm for Zigzag test are summarized in Table 8 .

TABLE VIII

NUMERICAL RESULTS OF OPTIMIZATION PROCEDURE BY APPLYING SIMPLEX ALGORITHM FOR ZIGZAG TEST.

\begin{tabular}{|c|c|}
\hline Parameter & Value \\
\hline $\begin{array}{c}\text { Objective Function Error: } \\
\left\|F_{o b j}^{i t e r}-F_{o b j}^{i t e r-1}\right\|\end{array}$ & $1 \times 10^{-4}$ \\
\hline $\begin{array}{c}\text { Optimization Variable Error: } \\
\text { Maximum Number of Iterations }\end{array}$ & $1 \times 10^{-4}$ \\
\hline $\begin{array}{c}\text { Minimum Value of Objective Function (minimized } 1.000): \\
F_{o b j}\end{array}$ & 410 \\
\hline $\begin{array}{c}\text { from-1 } \\
17.3 \mathrm{deg}):\end{array}$ & 0.318 \\
\hline$\psi_{(R M S D)}$ & $5.9 \mathrm{deg}$ \\
\hline
\end{tabular}

The optimal value of HCs obtained by Simplex algorithm in Zigzag test is presented in Table 9.

TABLE IX

OPTIMAL VALUE OF HCS OBTAINED BY SIMPLEX ALGORITHM IN ZIGZAG TEST.

\begin{tabular}{|c|c|c|c|}
\hline ID No. & Hyd. Coefficient & Initial Value & Optimal Value \\
\hline 5 & $Y_{T}^{\prime \prime}$ & 0.040 & 0.036 \\
\hline 6 & $N_{T}^{\prime \prime}$ & -0.020 & -0.050 \\
\hline 7 & $N_{\dot{r}}^{\prime \prime}$ & -0.0728 & -0.0787 \\
\hline 15 & $Y_{u r \xi}^{\prime \prime}$ & 0.182 & 0.046 \\
\hline 16 & $N_{u r \xi}^{\prime \prime}$ & -0.047 & -0.030 \\
\hline 22 & $N_{u v \xi}^{\prime \prime}$ & -0.241 & -0.258 \\
\hline 24 & $N_{c|c| \delta}^{\prime \prime}$ & -0.098 & -0.084 \\
\hline 32 & $X_{\mathrm{u}|\mathrm{u}|}^{\prime \prime}$ & -0.0377 & -0.0311 \\
\hline 33 & $N_{\dot{r} \xi}^{\prime \prime}$ & -0.0045 & -0.0059 \\
\hline 34 & $X_{|\mathrm{u}| \mathrm{u} \xi}^{\prime \prime}$ & -0.0061 & -0.0049 \\
\hline
\end{tabular}


It notes the remarkable minimum value of the Objective Function obtained by Simplex algorithm for Zigzag test after convergence, which is 0.318 (minimized from 1.000). This is a good optimization result and shows that Simplex algorithm can be applied to ship's yaw angle optimization problem.

3) Common value of OHCs of Turning Circle and Zigzag tests: After obtaining the value of OHCs from Turning Circle and Zigzag tests, a set of common values is identified by merging the optimal value of the most sensitive coefficients of two test (average value), for the remaining coefficients, the initial value is used. The set of common values above is used as the final value of ship's HCs for the other ship's motion simulation applications (Table 10).

TABLE X

SET OF COMMON VALUE OF OHCS.

\begin{tabular}{|c|c|c|c|c|c|}
\hline $\begin{array}{l}\text { ID } \\
\text { No. }\end{array}$ & $\begin{array}{c}\text { Hyd. } \\
\text { Coeff. }\end{array}$ & $\begin{array}{l}\text { Initial } \\
\text { Value }\end{array}$ & $\begin{array}{c}\text { Turning } \\
\text { Circle }\end{array}$ & Zigzag & $\begin{array}{c}\text { Common } \\
\text { Value }\end{array}$ \\
\hline 1 & $X_{\dot{u}}^{\prime \prime}$ & -0.05 & - & - & -0.05 \\
\hline 2 & $X_{v r}^{\prime \prime}$ & 1.020 & - & - & 1.020 \\
\hline 3 & $Y_{\dot{v}}^{\prime \prime}$ & -0.020 & - & - & -0.020 \\
\hline 4 & $Y_{|c| c|\beta| \beta \delta}^{\prime \prime}$ & -2.16 & - & - & -2.16 \\
\hline 5 & $Y_{T}^{\prime \prime}$ & 0.040 & - & 0.036 & 0.036 \\
\hline 6 & $N_{T}^{\prime \prime}$ & -0.020 & -0.018 & -0.050 & -0.034 \\
\hline 7 & $N_{\dot{r}}^{\prime \prime}$ & -0.0728 & - & -0.0787 & -0.0787 \\
\hline 8 & $Y_{|v| v}^{\prime \prime}$ & -2.4 & - & - & -2.4 \\
\hline 9 & $N_{|v| r}^{\prime \prime}$ & -0.3 & - & - & -0.3 \\
\hline 10 & $X_{|v| v}^{\prime \prime}$ & 0.3 & - & - & 0.3 \\
\hline 11 & $Y_{u v}^{\prime \prime}$ & -1.205 & - & - & -1.205 \\
\hline 12 & $N_{u v}^{\prime \prime}$ & -0.451 & - & - & -0.451 \\
\hline 13 & $X_{\dot{u} \xi}^{\prime \prime}$ & -0.05 & - & - & -0.05 \\
\hline 14 & $Y_{\dot{v} \xi}^{\prime \prime}$ & -0.378 & - & - & -0.378 \\
\hline 15 & $Y_{u r \xi}^{\prime \prime}$ & 0.182 & 0.212 & 0.046 & 0.129 \\
\hline 16 & $N_{u r \xi}^{\prime \prime}$ & -0.047 & -0.046 & -0.030 & -0.038 \\
\hline 17 & $X_{v r \xi}^{\prime \prime}$ & 0.378 & - & - & 0.378 \\
\hline 18 & $Y_{|v| v \xi}^{\prime \prime}$ & -1.5 & - & - & -1.5 \\
\hline 19 & $N_{v r \xi}^{\prime \prime}$ & -0.12 & - & - & -0.12 \\
\hline 20 & $Y_{|c| c \delta}^{\prime \prime}$ & 0.208 & 0.190 & - & 0.190 \\
\hline 21 & $Y_{u v \xi}^{\prime \prime}$ & 0 & - & - & 0 \\
\hline 22 & $N_{u v \xi}^{\prime \prime}$ & -0.241 & -0.233 & -0.258 & -0.246 \\
\hline 23 & $X_{c|c| \beta \delta}^{\prime \prime}$ & 0.152 & 0.190 & - & 0.190 \\
\hline 24 & $N_{c|c| \delta}^{\prime \prime}$ & -0.098 & -0.082 & -0.084 & -0.083 \\
\hline 25 & $X_{v v \xi \xi}^{\prime \prime}$ & 0.0125 & - & - & 0.0125 \\
\hline
\end{tabular}

\begin{tabular}{|c|c|c|c|c|c|}
\hline $\begin{array}{c}\text { ID } \\
\text { No. }\end{array}$ & $\begin{array}{c}\text { Hyd. } \\
\text { Coeff. }\end{array}$ & $\begin{array}{c}\text { Initial } \\
\text { Value }\end{array}$ & $\begin{array}{c}\text { Turning } \\
\text { Circle }\end{array}$ & Zigzag & $\begin{array}{c}\text { Common } \\
\text { Value }\end{array}$ \\
\hline 26 & $Y_{|c| c|\beta| \beta \delta}^{\prime \prime}$ & -2.16 & - & - & -2.16 \\
\hline 27 & $N_{|c| c|\beta| \beta \delta}^{\prime \prime}$ & 0.688 & - & - & 0.688 \\
\hline 28 & $Y_{|c| c|\beta| \beta \delta \xi}^{\prime \prime}$ & -0.191 & - & - & -0.191 \\
\hline 29 & $N_{|c| c|\beta| \beta|\delta| \xi}^{\prime \prime}$ & 0.344 & - & - & 0.344 \\
\hline 30 & $Y_{\mathrm{ur}}^{\prime \prime}$ & 0.248 & - & - & 0.248 \\
\hline 31 & $N_{\mathrm{ur}}^{\prime \prime}$ & -0.207 & -0.186 & - & -0.186 \\
\hline 32 & $X_{\mathrm{u}|\mathrm{u}|}^{\prime \prime}$ & -0.0377 & - & -0.0311 & -0.0311 \\
\hline 33 & $N_{\dot{r} \xi}^{\prime \prime}$ & -0.0045 & - & -0.0059 & -0.0059 \\
\hline 34 & $X_{|\mathrm{u}| \mathrm{u} \xi}^{\prime \prime}$ & -0.0061 & -0.0061 & -0.0049 & -0.0055 \\
\hline 35 & $X_{c|c| \delta \delta}^{\prime \prime}$ & -0.093 & -0.110 & - & -0.110 \\
\hline
\end{tabular}

\section{CONCLUSION}

By contributing the mathematical model of ship's motion, applying the numerical method and MATLAB, the authors programmed a ship's motion simulation program. In order to reduce the errors of ship's motion simulation, the optimization technique is applied. The important ship's motions including ship's trajectory and yaw angle were validated by using the experimental data at sea of Turning Circle and Zigzag tests. For the optimization procedure, the authors contributed the form of Objective Function, applying the Sensitivity Analysis technique and Simplex algorithm to filter and optimize the most sensitive HCs.

A good result of optimization resolutions was obtained. In Turning Circle test, after optimization, and the ship's simulation trajectory are close to the experimental trajectory with a RMSD of $5.8 \mathrm{~m}$, which reduced from an original value of $69 \mathrm{~m}$. By the same optimization procedure, in Zigzag test, the ship's simulation yaw angle is close to the experimental data with a RMSD of $5.9 \mathrm{deg}$, which reduced from an initial value of $17.3 \mathrm{deg}$. After analyzing the optimization solutions, we obtained the optimal value of the most sensitive HCs in each test. From these values, we identify a set of common values by merging the optimal value of the most sensitive coefficients of two test, which may be used for the other ship's motion simulation application. Finally, we would like to propose an optimization procedure by applying the Simplex algorithm to optimize the ship's motion simulation using the experimental maneuvering test data.

\section{ACKNOWLEDGMENT}

The authors are gratefully to the Vietnam Maritime University (VMU) for providing necessary research facilities during this research work.

\section{REFERENCES}

[1] Y. Sun and D. Jia, "Study on Safety of Up-righting Project for a Capsized Ship Model Based on Cable Tensions, Theoretical Model and Numerical Method Accounting for Dynamic Effect," Int. J. eNavigation Marit. Econ., vol. 10, pp. 62-75, 2018.

[2] V. T. Pham, "Using the Vector Autoregression Model to Determine the Relationship Between Some Macroeconomic Targets and The 
Volume of Goods Transported by Sea in Vietnam," Int. J. eNavigation Marit. Econ., vol. 13, pp. 43-49, 2019.

[3] D. H. Anh, "The breakthrough technology solutions for control and treatment oil spill on the sea: A short review," J. Mech. Eng. Res. Dev., vol. 42, no. 5, pp. 01-05, 2019.

[4] P. H. Hoang, A. T. Hoang, N. H. Chung, L. Q. Dien, X. P. Nguyen, and X. D. Pham, "The efficient lignocellulose-based sorbent for oil spill treatment from polyurethane and agricultural residue of Vietnam," Energy Sources, Part A Recover. Util. Environ. Eff., vol. 40, no. 3, pp. 312-319, 2018.

[5] V. C. Huynh and G. T. Tran, "Improving the Accuracy of Ship Resistance Prediction Using Computational Fluid Dynamics Tool," Int. J. Adv. Sci. Eng. Inf. Technol., vol. 10, no. 1, pp. 171-177, 2020.

[6] H. Yasukawa and Y. Yoshimura, "Introduction of MMG standard method for ship maneuvering predictions," J. Mar. Sci. Technol., 2015.

[7] K. Wang, S. Wang, L. Zhen, and X. Qu, "Ship type decision considering empty container repositioning and foldable containers," Transp. Res. Part E Logist. Transp. Rev., vol. 108, pp. 97-121, 2017.

[8] S. Luo, N. Ma, and Y. Hirakawa, "Evaluation of resistance increase and speed loss of a ship in wind and waves," J. Ocean Eng. Sci., 2016.

[9] M. Duan, Z. Liu, D. Yan, W. Peng, and A. Baghban, "Application of LSSVM algorithm for estimating higher heating value of biomass based on ultimate analysis," Energy Sources, Part A Recover. Util. Environ. Eff., vol. 40, no. 6, pp. 709-715, Mar. 2018.

[10] J. Wang, L. Zou, and D. Wan, "Numerical simulations of zigzag maneuver of free running ship in waves by RANS-Overset grid method," Ocean Eng., vol. 162, pp. 55-79, 2018.

[11] W. Luo and L. Lan, "Design Optimization of the Lines of the Bulbous Bow of a Hull Based on Parametric Modeling and Computational Fluid Dynamics Calculation," Math. Comput. Appl., vol. 22, no. 1, p. 4, 2017.

[12] V. V. Pham and A. T. Hoang, "Technological perspective for reducing emissions from marine engines," Int. J. Adv. Sci. Eng. Inf. Technol., vol. 9, no. 6, pp. 1989-2000, 2019.
[13] T. Khanh Toan, "A Study on ship manoeuvring simulation and ship trajectory optimization based on SQP and BFGS algorithms from sea trials," Int. J. Eng. Technol., vol. 7, no. 4, pp. 103-111, 2018.

[14] B. Rudloff, F. Ulus, and R. Vanderbei, "A parametric simplex algorithm for linear vector optimization problems," Math. Program., vol. 163, no. 1-2, pp. 213-242, 2017.

[15] F. Huang, L. Wang, and C. Yang, "A new improved artificial bee colony algorithm for ship hull form optimization," Eng. Optim., vol. 48, no. 4, pp. 672-686, 2016.

[16] T. K. Toan, D. P, O. A, and S. P, "Simulation of ship manoeuvring in confined waterway using a nonlinear model based on optimization techniques," Ocean Eng., vol. 142, pp. 194-203, 2017.

[17] X. P. Nguyen and D. K. Pham Nguyen, "Experimental Research on the Impact of Anchor-Cable Tensions in Mooring Ship at Vung Tau Anchorage Area," Int. J. Adv. Sci. Eng. Inf. Technol., vol. 9, no. 6, pp. 1892-1899, 2019.

[18] F. Tillig and J. W. Ringsberg, "A 4 DOF simulation model developed for fuel consumption prediction of ships at sea," Ships Offshore Struct., vol. 14, no. sup1, pp. 112-120, 2019.

[19] T. Khanh Toan, "A Study on the Application of Sensitivity Analysis for Ship Hydrodynamic Coefficients," Int. J. Eng. Technol., vol. 7, no. 4, pp. 953-956, 2018.

[20] T. Tezdogan, Y. K. Demirel, P. Kellett, M. Khorasanchi, A. Incecik, and O. Turan, "Full-scale unsteady RANS CFD simulations of ship behaviour and performance in head seas due to slow steaming," Ocean Eng., 2015.

[21] T. K. Toan, O. A., N. H., H. F., and A. Pourplanche, "A fast simulation and identification of hydrodynamic parameters for a freely maneuvering ship vessels," in International Conference on Multiphysics - MULTIPHYSICS 2009, 2009, pp. 09-11.

[22] H. Guo and Z. Zou, "System-based investigation on 4-DOF ship maneuvering with hydrodynamic derivatives determined by RANS simulation of captive model tests," Appl. Ocean Res., vol. 68, pp. 11$25,2017$. 